\title{
THE
}

2014

\section{Are Fulbright Applicants Idealists or Opportunists?}

Corey Lang

University of Rhode Island, clang@uri.edu

Carrie Gill

Follow this and additional works at: https://digitalcommons.uri.edu/enre_facpubs

Part of the Labor Economics Commons

The University of Rhode Island Faculty have made this article openly available.

Please let us know how Open Access to this research benefits you.

This is a pre-publication author manuscript of the final, published article.

Terms of Use

This article is made available under the terms and conditions applicable towards Open Access Policy Articles, as set forth in our Terms of Use.

\section{Citation/Publisher Attribution}

Gill, Carrie and Corey Lang. "Are Fulbright Applicants Idealists or Opportunists?" Eastern Economic Journal, May 19 2014. DOI: 10.1057/eej.2014.26. Available: http://www.palgrave-journals.com/eej/ journal/vaop/ncurrent/full/eej201426a.html

This Article is brought to you for free and open access by the Environmental and Natural Resource Economics at DigitalCommons@URI. It has been accepted for inclusion in Environmental and Natural Resource Economics Faculty Publications by an authorized administrator of DigitalCommons@URI. For more information, please contact digitalcommons-group@uri.edu. 


\title{
Are Fulbright Applicants Idealists or Opportunists?
}

\author{
Carrie Gill and Corey Lang* \\ University of Rhode Island
}

March 25, 2014

\begin{abstract}
The Fulbright program attracts applicants passionate about service and research abroad. Applicants apply to one country. To aid their decisions, competition statistics giving approximate probabilities of being awarded a scholarship are released for each country. This paper examines how competition statistics influence country choices. In aggregate, our results suggest that applicants are not swayed to apply to countries with low competition or deterred from countries with high competition. However, accounting for the difference in scholarship types and the macroeconomic context, there is strong evidence of opportunistic behavior by teaching applicants and for all applicants when the unemployment rate is high.
\end{abstract}

Keywords: signals; competition behavior; decision making; Fulbright

JEL: D83; I2

\footnotetext{
"Corresponding author. 214 Coastal Institute, 1 Greenhouse Rd., Kingston, RI, 02881. Email: clang@mail.uri.edu. We thank Elizabeth Edmondson, Walter Jackson, Ae Rin Jung, Kathleen Maher, and Brigid Shipman for help collecting data and understanding the Fulbright application process. We appreciate valuable comments from Amanda Griffith, Nicholas Logler, Kyle Montanio, Joe Price, and two anonymous referees. Thanks to Michelle Peach Lang for suggesting the title of the paper. This paper is a contribution of the Rhode Island Agricultural Experiment Station (\#5361).
} 
Guess how many people applied to Kenya last year? Zero!

- Brendan Lang, summer 2011, while contemplating a Fulbright application

\section{Introduction}

The Fulbright U.S. Student Program is designed to attract students who are passionate about cultural understanding and strive to be ambassadors for the United States. Having a Fulbright Scholarship on one's resume is a well-recognized signal of prestige to potential employers or graduate programs. Equally as important, the award consists of living and travel expenses, which can be precious for someone just graduating from college or a graduate student short on funding. For these reasons, the Fulbright Program is an interesting combination of passion and competition.

The Fulbright Program only allows applicants to apply to a single country for either a Research Grant or an English Teaching Assistantship (ETA). Potentially to aid the decision over which country, the administering body for the Fulbright Program provides applicants with statistics about how competitive each country was the prior year. This paper examines whether applicants use these statistics to make strategic choices about the country to which they apply. In essence, does their passion for a single country obviate probabilities, or do they exploit opportunities?

To answer this question, we collected data on the Fulbright U.S. Student Program for 68 countries from 2002 to 2008. Specifically, the Fulbright Program releases data on the number of applicants and grants awarded the previous year, and the number of grants available for the upcoming year for each country and scholarship type. Our empirical model tests whether the reported competition statistics from the previous year impact the country choices of applicants the following year.

In a basic specification, our results suggest that applicants do not behave strategically on average; low competition in the prior year does not induce additional applicants to apply to a country and high competition does not deter applicants from a country. Moving beyond the basic specification, we explore heterogeneity in responses to competition statistics with respect to the type of grant and the economic context at the time of the application decision (specifically, the unemployment rate). These results suggest that ETA applicants have a statistically significant negative response to reported competition - ETA applicants are dissuaded from applying to countries with high competition and are attracted to countries with low competition. In contrast, 
reported competition does not appear to be a significant factor in the country choices of Research applicants. However, when we account for the unemployment rate, we find that higher-thanaverage unemployment rates elicit opportunistic strategies from both Research and ETA applicants. That is, both types of applicants appear to factor reported competition into their country choices; on average, applicants prefer to apply to less competitive countries over countries with high reported competition rates.

This paper contributes to literature examining how individuals respond to signals of competition. The most related research is by Price (2008), who examines how doctoral students responded to competitive funding from the Mellon Foundation tied to the speed of progress through their program. Beyond competition, there has been a rich literature examining responses to signals of quality. For example, Monks and Ehrenberg (1999) find that a college's ranking in the U.S. News and World Report impacts admission rates, yield rates, and average SAT scores of the incoming class and Pope (2009) shows that an increase in hospital ranking leads to an increase in patient volume and hospital revenue. Furthermore, McDonough et al. (1998) show that high achieving students, our likely applicant pool, are more likely to consider college rankings in their decisions than low achieving students. Much of this body of literature explores the impacts of Kahneman and Tversky’s (1982) finding that people rely on heuristics and simplifications to process detailed information. Despite Fulbright's statistics being presented as raw numbers, we find that they still influence applicant behavior.

Another vein of research that we contribute to examines heterogeneity in the response to signals. Beyond what was mentioned in the previous paragraph, Price (2008) examines gender differences and finds a sharp contrast that the effect of competition reduces men's time to doctoral candidacy but not women’s. Griffith and Rask (2007) examine heterogeneity in responses to college rankings and find that they impact application decisions less for women, minorities, and high-ability students than the average applicant. Bar et al. (2009) study college course selection when median course grades from previous semesters are posted online. They find that students with less academic ability (as represented by SAT scores) choose courses with higher previous median grades, whereas students with high academic ability choose courses with lower previous median grades. While previous literature has explored the influences of individual-level characteristics like demographics, we add to the literature by examining heterogeneous responses to competition in the context of external situation-specific influences. 
To the best of our knowledge, this paper is the first to examine and show that economic context affects responses to information.

The paper proceeds as follows. In Section 2 we provide background on the Fulbright Scholar Program and relevant information about Fulbright grants. We lay out our empirical method in Section 3 and describe our dataset in Section 4. We discuss our results in Section 5 and make concluding remarks in Section 6.

\section{Background on the Fulbright Scholar Program}

The Fulbright Scholar Program is a foreign exchange program that funds students and professionals to conduct research, study, or teach for one year abroad. Established in 1946 by President Truman, the program is administered through the U.S. Department of State Bureau of Educational and Cultural Affairs. According to the Institute of International Education (IIE), the Fulbright Scholar Program awards approximately 8,000 grants annually for U.S. citizens to study in over 155 countries and for foreign scholars to study in the United States. Awards are funded through congressional appropriations (\$237.6 million in 2012) and through support from foreign governments (U.S. Department of State 2013). There have been many notable Fulbright Scholars, including Nobel laureates, MacArthur Foundation Fellows, Pulitzer Prize winners, and heads of government (U.S. Department of State 2013).

Our study focuses on the Fulbright U.S. Student Program, which is a subset of the Fulbright Scholar Program specifically for American college students and recent graduates to study or teach abroad for one year. Types of grants include Research grants and English Teaching Assistantship (ETA) grants, among others (IIE 2013). ${ }^{1}$ Research grant awardees design and implement a research project and work in collaboration with an advisor at a university in the host country. ETA grant awardees work closely with an English teacher in the host country to help teach the language and serve as “cultural ambassadors for U.S. culture” (IIE 2013). Grant benefits include round trip travel, room and board in the host country, incidental costs during the scholarship year, and health benefits, as well as intangible benefits such as networking opportunities and perceived prestige.

\footnotetext{
${ }^{1}$ Other Fulbright U.S. Student Program grants include Fulrbight-mtvU Awards to study musical culture, Fulbright Public Policy Fellowships to work in public offices alongside conducting research, and travel grants to supplement external funding for research. We do not include these programs in our research because statistics for them are unavailable.
} 
The application process for the Fulbright U.S. Student Program is extensive. Figure 1 illustrates the sequence of events and deadlines in the application process. As outlined by the IIE, applicants are required to apply to the country of their interest and are able to begin their applications in May of the year prior to the grant award. Application deadlines are between August and October and vary by university. Applicants first submit applications to their university coordinators. Universities select the best applications to submit to Fulbright committees for consideration. Successful applicants are selected between March and May of the award year and their Fulbright scholarships begin in the fall. Through conversations with Fulbright coordinators at two universities, we learned that due to the amount of work required to apply, applicants typically only apply once.

According to IIE guidelines, applicants must provide biographical data, a one-page personal statement, an evaluation of foreign language skills (if applicable), three references, and official transcripts. Each ETA applicant must also submit a one-page Statement of Grant Purpose detailing how she will assist with teaching English and how she will be an ambassador of American culture. Each Research applicant also must submit a Statement of Grant Purpose, but her statement must be two pages and outline the research project she intends to conduct in the host country. In addition, each Research applicant must submit an Affiliation Letter from an advisor in the host country.

Each year, the IIE publishes a book detailing the Fulbright U.S. Student Program and all of the specific details for each country. These books are widely available to individuals interested in applying to the program and are freely distributed at Fulbright information sessions.

IIE's book explicitly provides a table of competition statistics, which includes the number of applicants and grants awarded for each country in the previous year alongside the number of grants being offered for that country for the current application year. To get a sense of how applicants view the competition statistics, Figure 2 presents a copy of this page from the IIE book. Only applicants who are selected by their universities to submit their applications are included in the statistics. University coordinators highlight these statistics as an indication of the chances of a successful application for potential Fulbright applicants (Maher 2012). 


\section{Empirical Approach}

We are interested in whether or not the reported competition statistics from the previous year impact the country choices of applicants. The basic econometric model is:

$$
\begin{gathered}
\ln \left(\text { realized } \text { competition }_{c, t}\right)=\beta \ln \left(\text { reported } \text { competition }_{c, t-1}\right) \\
+X_{c, t-1} \gamma+\alpha_{c}+\tau_{t}+\alpha_{c} \cdot t+\varepsilon_{c, t}
\end{gathered}
$$

The dependent variable is realized competition ${ }_{c, t}$, which we define as the number of applications received for country $c$ in year $t$ divided by the number of grants advertised for that country and year. The number of applicants is recorded in the following year's competition statistics and the number of grants offered is recorded in the current year's competition statistics. The key independent variable is reported competition ${ }_{c, t-1}$, which we define as the number of applicants divided by the number of grants for the previous year as reported in the current year's competition statistics. While competition is not explicitly reported in the IIE publication, we feel it best captures the relevant signal. ${ }^{2}$ Interestingly, realized competition ${ }_{c, t}$ does not necessarily equal reported competition $n_{c, t}$. For $9.3 \%$ of observations, the number of grants advertised as being offered in the upcoming year differs from the actual number of grants awarded that year, as indicated by the following year's competition statistics. Because we are interested in responses to reported competition, it is critical that we use reported competition ${ }_{c, t-1}$ as our key explanatory variable instead of realized competition $_{c, t-1}$. To correct for the skewness of the kernel density of competition and to facilitate interpretation of results, we transformed both measures of competition by taking the natural log.

The coefficient of interest, $\beta$, is interpreted as the percent change in realized competition resulting from a $1 \%$ change in reported competition for the prior year. If our coefficient of interest is zero or insignificant, then there is no correlation in competition in subsequent years. A positive $\beta$ indicates that high competition begets high competition. For both scenarios where $\beta$ is non-negative we can infer that Fulbright applicants are probably idealists; they apply to the countries in which they are most interested regardless of their odds of successfully receiving grants. On the other hand, a negative $\beta$ indicates that applicants chose where to apply in a strategically opportunistic way. A negative correlation implies that a country with low

\footnotetext{
${ }^{2}$ We additionally perform the analysis using reported statistics only and results are similar though more difficult to interpret. In recent years, the IIE has started to present competition statistics as "Applications / Awards", which further supports our use of reported and realized competition in our models.
} 
competition rates one year attracts more applicants the following year. Conversely, a highly competitive country deters applicants the following year, resulting in a decreased level of competition.

Also included in our model is a vector of covariates, $X_{c, t-1}$, for each country from the previous year, including GDP per capita, population, measures of political freedom, and an article count in The Economist meant to capture current events that may influence applicants. See the data section for a thorough description of the control variables. Additionally, we add country fixed effects to account for unobserved, time-invariant differences that might impact the appeal of each country. We add year fixed effects to capture year-specific shocks in the number of applicants and grants. Finally, we add country-specific time trends to capture longer-term changes in a country's popularity among applicants.

We then explore strategic behavior for Research and ETA applicants separately. We believe that their strategic behavior may differ for two reasons. First, the two types of grants may attract applicants with different career goals. Research applicants pursue specific knowledge, perhaps for an advanced degree or a profession that requires research skills. ETA applicants may be open to a wider variety of career options following their Fulbright experiences. Second, application for Research grants requires more detail in the Statement of Grant Purpose than the ETA application, as well as an Affiliation Letter from an advisor in the country of application. These additional requirements suggest that prior familiarity with the country of application might be beneficial to Research applicants. For these reasons, Research applicants may be less influenced by competition rates than ETA applicants.

We also examine how strategic behavior may change as a function of the larger macroeconomic context during the application process. Our intuition is that if the availability of alternative employment or funding for potential applicants is scarce, then competition will be heightened. We use the US unemployment rate as our measure of macroeconomic strength.

Taking into account both sources of heterogeneity (grant type and unemployment rate), the second model is: 


$$
\begin{aligned}
& \ln (\text { realized competition } \text { ce,t })=\beta_{1} \ln \left(\text { reported }_{\text {competition }} \text { re,t-1 }\right) \\
& +\beta_{2} \ln (\text { reported competition } \text { ce,t-1 }) \cdot \text { unemp }_{t-1} \\
& +\beta_{3} \ln (\text { reported competition } \text { ce,t-1 }) \cdot D_{c e, t}(e=1) \\
& +\beta_{4} \ln (\text { reported competition } \text { ce,t-1 }) \cdot \text { unemp }_{t-1} \cdot D_{c e, t}(e=1) \\
& +X_{c e, t-1} \gamma_{e}+\alpha_{c e}+\tau_{e, t}+\alpha_{c e} * t+\varepsilon_{c e, t}
\end{aligned}
$$

where $e$ is an index for grant type, $u n e m p_{t-1}$ is the average U.S. unemployment rate for the year leading up to the application deadline, and $D_{c e, t}(e=1)$ is a dummy variable for ETA grant applicants (the excluded variable is for Research applicants). In this model, $X$ includes unemployment and the interaction of unemployment with the dummy variable for ETA grant applicants.

\section{Data}

\subsection{Fulbright Data}

Data about the number of Fulbright applicants and grants awarded annually for each country is publically available through the Institute of International Education's (IIE) annual publication, Fulbright U.S. Student Program: Grants for Graduate Study, Research, or Teaching Assistantships Abroad. This book contains the number of applicants and grants awarded the previous year, and the number of grants available for the upcoming year for each country and scholarship type. The timing of our key competition variables is illustrated in Figure 1.

We compiled data for 68 countries from 2002 through 2008. ${ }^{3}$ While data for 1996 through 2011 are available, we restrict the years for the following reasons. Prior to 2002, grant type (ETA or Research) was not reported. After 2008, the number of ETA grants awarded in the prior year stopped being presented alongside the other statistics.

Panel A of Table 1 presents an overview of observations in our dataset. At the countryyear level, we have 463 observations over 68 countries. We have all seven years of data for 64 of those countries; the remaining countries have at least three years of data. When the data is decomposed by grant type, we have a total of 580 observations. There are 125 observations for

\footnotetext{
${ }^{3}$ While the Fulbright U.S. Student Program sends Fulbrighters to about 140 countries, about 70 of those countries are included in "Regional Programs". While applicants still apply to a particular country, grants are allocated on a regional basis. Statistics reported for the Regional Programs include the number of applications received for each country and the number of grants awarded and offered for the region as a whole. We compiled data for the 68 countries for which the Fulbright U.S. Student Program provides country-specific data.
} 
ETA grants over 29 countries, resulting in an average of 4.31 observations per country. There are 455 observations for Research grants over 66 countries, resulting in an average of 6.89 observations per country.

The number of applicants to the Fulbright U.S. Student Program increased every year except for 2004 and 2005. The biggest increase in applicants was in the 2008 applicant pool, which jumped by 613 applicants. The number of grants offered increased every year, ranging from an increase of 2 grants in 2008 to an increase of 124 grants in 2007. The mean rate of competition ranges from 5.26 in 2005 to 6.03 in 2008.

Forty-seven out of the 68 countries in our dataset have mean competition rates below the overall average. A few countries with very high competition rates skew the overall average upward. The countries with higher-than-average competition rates include the United Kingdom and Ireland, which average 25.82 and 16.97 applicants for each grant offered, respectively. Latvia and Lithuania have the lowest average competition rates, 1.82 and 2.09 applicants for each grant offered, respectively.

There is a difference in mean competition rates over time for each grant type. Figure 3 shows mean competition rates for ETA and Research grants from 2002 to 2008. We weight our mean by the number of applications submitted in the previous year for each country. We use this weight because we are interested in individual behavior but are using aggregate data. Competition rates for Research grants are consistently higher than competition rates for ETA grants. Average competition for Research grants approaches 10 applicants per grant offered in 2004, dips in 2005, and slowly increases again through 2008. Mean competition for ETA grants shows an increasing trend over the time range.

\subsection{Additional Data}

We collected country-year-specific demographic and political data to include in our model as control variables. There are many factors that influence which country applicants choose, and we may be able to capture some of that variation with additional variables. The timing of the control variables in relation to the Fulbright application process is illustrated in Figure 1. A summary of all covariate data is included in Panel B of Table 1.

We include population data and gross domestic product (GDP) per capita to reflect the relevance and affluence of each country. Population and GDP per capita data are from the World 
Bank. ${ }^{4}$ We include dummy variables indicating political freedom as a measure of security and strife in each country. Freedom Index data is from Freedom House. We included a count of the number of articles about each country in The Economist during the year leading up to the application deadline. We used The Economist as a proxy for gauging interest in countries. We determined article count by performing a subject search of the country name in the ABI/INFORM database for articles published within the year prior to the first application deadline (August of each year).

We collected U.S. unemployment rate data from the U.S. Bureau of Labor Statistics. We averaged monthly U.S. unemployment rates from August in year $t-2$ through July of year $t-1$; in other words, we used an average unemployment rate for the year leading up to the first application deadline. Figure 4 shows mean competition (weighted by applications received the previous year) and average annual U.S. unemployment rate from 2002 to 2008. Mean competition and unemployment rate both decreased from 2003 to 2007 and then showed an increase in 2008.

\section{Results}

In this section, we present our results. We first present basic models in section 5.1. Then, we explore the impacts of unemployment rate on strategic behavior in section 5.2. Finally, we examine differences in strategic behavior between applicants by grant type in section 5.3.

\subsection{Determining the base model}

Table 2 presents our results from examining the effect of reported competition on realized competition. Each model uses weighted least squares with weights equal to the number of applications received in the previous year. We use this weight because we are interested in individual behavior but are using aggregate data.

There are five columns, and each adds something to the model. Column 1 shows our regression results using a simple pooled OLS regression. The coefficient of interest, $\beta$ in Equation (1) equals 0.879 and is highly statistically significant in Column 1 . This is literally interpreted as a $1 \%$ increase in reported competition increases competition by $0.879 \%$ the

\footnotetext{
${ }^{4}$ Population and GDP per capita data for Taiwan are not available from the World Bank; instead, we collected Taiwan's data from Index Mundi.
} 
following year. This result suggests that highly competitive countries, like Ireland and the United Kingdom, continue to be popular despite being highly competitive. Conversely, less competitive countries, like Latvia and Lithuania, continue to be less popular despite being less competitive. This estimate combined with the remarkably high adjusted r-squared value indicate that competition levels are fairly stable over time, but not perfectly so.

In Column 2, we add country fixed effects to account for unobserved heterogeneity. With this addition, $\beta$ is now identified from within-country variation in competition, rather than between-country variation. The estimate of $\beta$ declines dramatically to 0.167 and is now only significant at the $10 \%$ level. This is consistent with our explanation of the Column 1 result because we expected the level of competition to have large between-country variation. In Columns 3 and 4, we add the vector of covariates to capture the impact of time-varying characteristics at the country-level and year fixed effects, respectively. Both have small attenuating effects on $\beta$.

The small positive coefficients in Columns 2 through 4 suggest that Fulbright applicants do use the competition information to make country choices, but do so perversely; applicants are more likely to apply to countries when their competition rates are higher than the countryspecific average. However, this result could represent momentum in a country’s popularity. To address this possibility, Column 5 includes a country-specific time trend. ${ }^{5}$ Now, the coefficient of interest is -0.008 and statistically insignificant. This result suggests that a country's reported competition has essentially zero effect on realized competition the following year. ${ }^{6}$ Of all models shown in Table 2, Column 5 minimizes both Akaike Information Criterion (AIC) and the Bayesian Information Criterion (BIC). For this reason, Column 5 is our preferred model and will be used to further examine behavior differences between types of applicants and in relation to U.S. unemployment.

\footnotetext{
${ }^{5}$ As an alternative way to model growing or declining interest in a country, we considered using multiple lag terms for competition. However, we ultimately decided that including competition from the previous year only was the most accurate representation of signals received by potential applicants, since statistics from the previous year were the only statistics published throughout the years in our dataset.

${ }^{6}$ While we believe a weighted regression is most appropriate for this regression, because it best approximates individual behavior with aggregate data, it is still worthwhile to estimate an unweighted model. Unweighted, the regression of Column 5 yields a statistically significant coefficient of -0.287 on $\ln$ (reported competition). While this result is suggestive of heterogeneity by applicant pool size, we did not find evidence of this heterogeneity in our weighted framework using models with interactions based on program size.
} 


\subsection{Heterogeneity in strategic behavior by unemployment rate and type of grant}

Table 3 presents results of estimating four versions of Equation (2). The first column examines heterogeneity in responses to competition due to the unemployment rate, and this model uses the same data used in Table 2. Columns 2 through 4 use data at the country-type-year level and examine differences in responses to competition by type of grant (Research or ETA) and the combination of unemployment and type of grant, respectively.

In Column 1, the coefficient on the interaction between reported competition and unemployment is -0.058 and statistically significant, which suggests that a $1 \%$ increase in unemployment decreases the elasticity of competition by nearly 0.06 . The change in response to competition may reflect a change in individual behavior. Intuitively, when unemployment is high and opportunities are scarcer, individual applicants may be more likely to be dissuaded from applying to a country that has a competition rate higher than its country-specific average. Alternatively, this negative coefficient could represent a change in the composition of the applicant pool. The applicant pool may consist of a "core" group of applicants and a "marginal" group of applicants. The core group is less apt to be swayed to apply or not based on unemployment rate but is responsive to changes in competition; a member of the core group will apply regardless of the unemployment rate but will factor in competition when choosing a country. Conversely, the marginal group is more responsive to unemployment and less responsive to competition; a member of the marginal group will only apply when unemployment is low but will apply to whatever country she prefers most, regardless of competition. The coefficients on the reported competition and unemployment are both insignificant ${ }^{7}$.

Column 2 presents the results from the analysis of how strategic behavior differs between applicants for ETA and Research grants. The coefficient on reported competition, which in this model is the response for Research applicants only, is similar in magnitude (0.044) and insignificance to Column 5 of Table 2. However, the coefficient on reported competition interacted with the ETA dummy is -0.405 and statistically significant. This suggests responses to

\footnotetext{
${ }^{7}$ Although the coefficient on unemployment is insignificant, it's negative sign suggests that competition decreases as unemployment increases. Further analysis of applications on unemployment and grants on unemployment tenuously suggest that both decrease when unemployment increases, but applications decrease more so.
} 
competition are significantly different for the two types of grants. While Research applicants appear indifferent to competition, ETA applicants have an elasticity of $-0.361 .{ }^{8}$

Columns 3 and 4 present results that combine heterogeneity by the unemployment rate and by grant type. The results of Column 3 essentially replicate the coefficients from Columns 1 and 2. Again, the unemployment rate elicits strategic behavior among applicants when it is high and ETA applicants are far more concerned with competition than Research applicants. Column 4 additionally allows the competition response to vary by unemployment and grant type in a multiplicative fashion, not just additive; this is Equation (2) in its entirety. The coefficients on reported competition and reported competition interacted with unemployment are nearly unchanged from Columns 1 and 3. Again, the results suggest that the effect of reported competition is heightened when the unemployment rate is high. When competition and competition interacted with unemployment are also interacted with ETA, the coefficients are both negative, which is the same sign as the coefficients on the main effects. This suggests that the unemployment rate induces an even stronger effect of competition on ETA applicants. However, both of these coefficients are statistically insignificant, indicating no statistical difference in responses between the two groups, but the signs of the coefficients are suggestive and fit with intuition derived from earlier results. Lastly, we see the unemployment rate has a strong, positive, statistically significant effect on overall competition for ETA applicants which suggests that the number of ETA applicants increases dramatically in high unemployment years. The significance of this coefficient is a stark contrast to the insignificance of the coefficient on unemployment in Columns 1 and 4, suggesting there is no such effect on Research applicants. This result again highlights the differences between these types of applicants. ${ }^{9}$

\footnotetext{
${ }^{8}$ While negative correlation between competition rates in subsequent years could appear to be mean reversion, we believe the effect is due to reported competition. First, the coefficient of interest in our preferred model is both small and insignificant. This coefficient would be nonzero and significant if mean reversion were the cause. Second, there is a significant correlation with an exogenous variable, U.S. unemployment rate. Coefficients on exogenous variables would be insignificant in the case of mean reversion.

${ }^{9}$ Another explanation for the difference in strategic application behavior between ETA and Research applicants could be the differences in language requirements. The Fulbright U.S. Student Program either recommends or requires that applicants can speak the local language of some countries (other countries, for example Anglophone countries, do not have any language recommendation or requirement). After a cursory exploration, we could not make any conclusions about the effect of language requirements on competition. However, this was mainly limited by the size of our dataset. Future research could explore the effect of language requirements and how this effect varies between ETA and Research applicants.
} 


\section{Conclusion}

This paper examines the motivations of Fulbright applicants’ country choices, specifically how reported statistics about competition influence these choices. Applicants can ignore this information and apply to their ideal country or they can exploit this information to increase their odds of success. Our specific motivation is to understand the strategic behavior of Fulbright applicants. More generally, our results shed light on how applicants respond to competition signals. We also show that external situational characteristics, specifically unemployment, may impact decision-making behavior.

We analyze data for 68 countries from 2002 to 2008. In aggregate, our results offer no evidence of opportunistic behavior. However, when we account for the differences in the type of applicant and the macroeconomic context in which the country choice is made, there is strong evidence of strategic behavior in response to competition signals by Teaching applicants and for all applicants when the unemployment rate is high.

While there are several possible motivations for the IIE to publish competition statistics, seemingly the most likely is for the statistics to encourage applicants to apply to less competitive (popular) countries. Increasing competition for low competition countries may increase the quality of Fulbright scholars for those countries without affecting quality in the high competition countries, which in turn could improve the diplomatic mission of the Fulbright Program. What do our results say about whether this goal was accomplished? On the one hand, we find empirical evidence that applicants are deterred from high competition countries. On the other hand, this result is only realized after including country fixed effects, suggesting that countries have a largely fixed amount of desirability that is unwavering even in the presence of competition. Thus, while our results do support the motivation to publish competition statistics, the strategic behavior we observe is small relative to the amount of non-strategic behavior exhibited by applicants. However, we speculate that this strategic behavior would be more prominent if Fulbright were to rank countries in order of competitiveness rather than or in addition to presenting raw statistics. 


\section{References}

Bar, Talia, Vrinda Kadiyali, and Asaf Zussman. (2006). “Grade Information and Grade Inflation: The Cornell Experiment.” Journal of Economics Perspectives, 23(3): 93-108.

Griffith, Amanda, and Kevin Rask. (2007). “The Influence of the US News and World Report Collegiate Rankings on the Matriculation Decision of High-ability Students: 1995-2004.” Economics of Education Review, 26(2), 244-255. doi:10.1016/j.econedurev.2005.11.002.

Institute of International Education (IIE). (2013). "Fulbright U.S. Student Program.” Fulbright U.S. Student Program, retrieved July 15, 2013 from http://us.fulbrightonline.org.

Kahneman, Daniel, Paul Slovic, and Amos Tversky. (1982). Judgment Under Uncertainty: Heuristics and Biases, New York, NY: Cambridge University Press.

Maher, Kathleen. “Personal Communication,” July 11, 2012.

McDonough, Patricia, Anthony Antonio, MaryBeth Walpole, and Leonor Perez. (1998).

“College rankings: Democratized college knowledge for whom?” Research in Higher Education, 39(5): 513-537.

Monks, James, and Ronald G Ehrenberg. (1999). “U.S. News \& World Report’s College Rankings: Why Do They Matter.” Change, 31(6).

Pope, Devin G. (2009). “Reacting to Rankings: Evidence from 'America’s Best Hospitals'.” Journal of Health Economics, 28(6), 1154-1165. doi:10.1016/j.jhealeco.2009.08.006.

Price, Joseph. (2008). “Gender Differences in the Response to Competition.” Industrial and Labor Relations Review, 61(3): 320-333.

U.S. Department of State. (2013). “The Fulbright Program.” Bureau of Educational and Cultural Affairs, retrieved July 15, 2013 from http://eca.state.gov/fulbright. 


\section{Figures and Tables}

Figure 1: Timeline of the Fulbright application process and illustration of timing of covariates

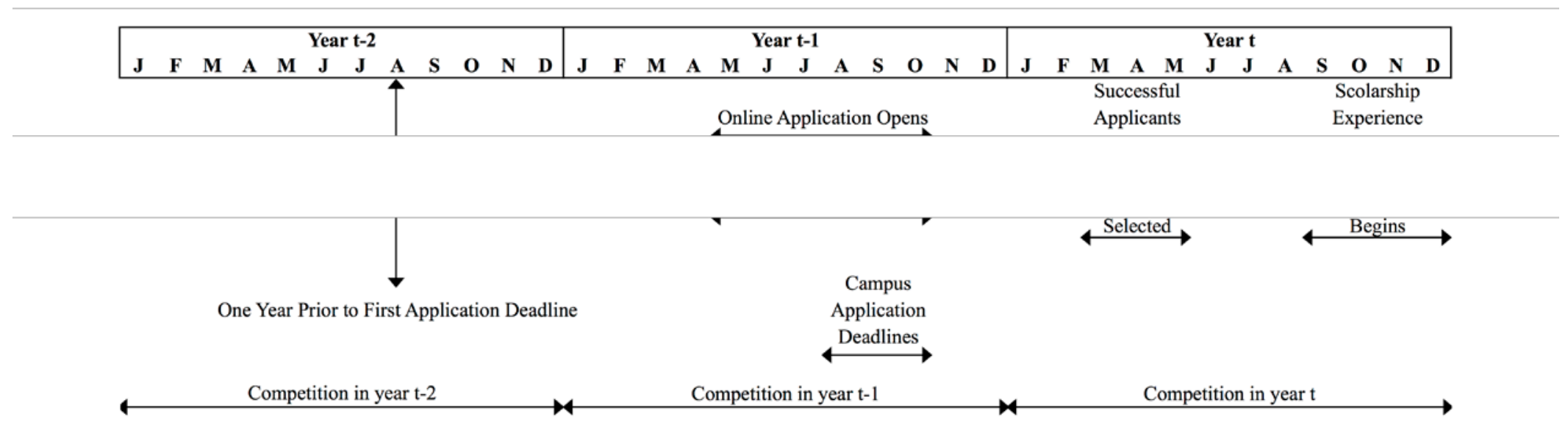


Figure 2: Reported competition statistics

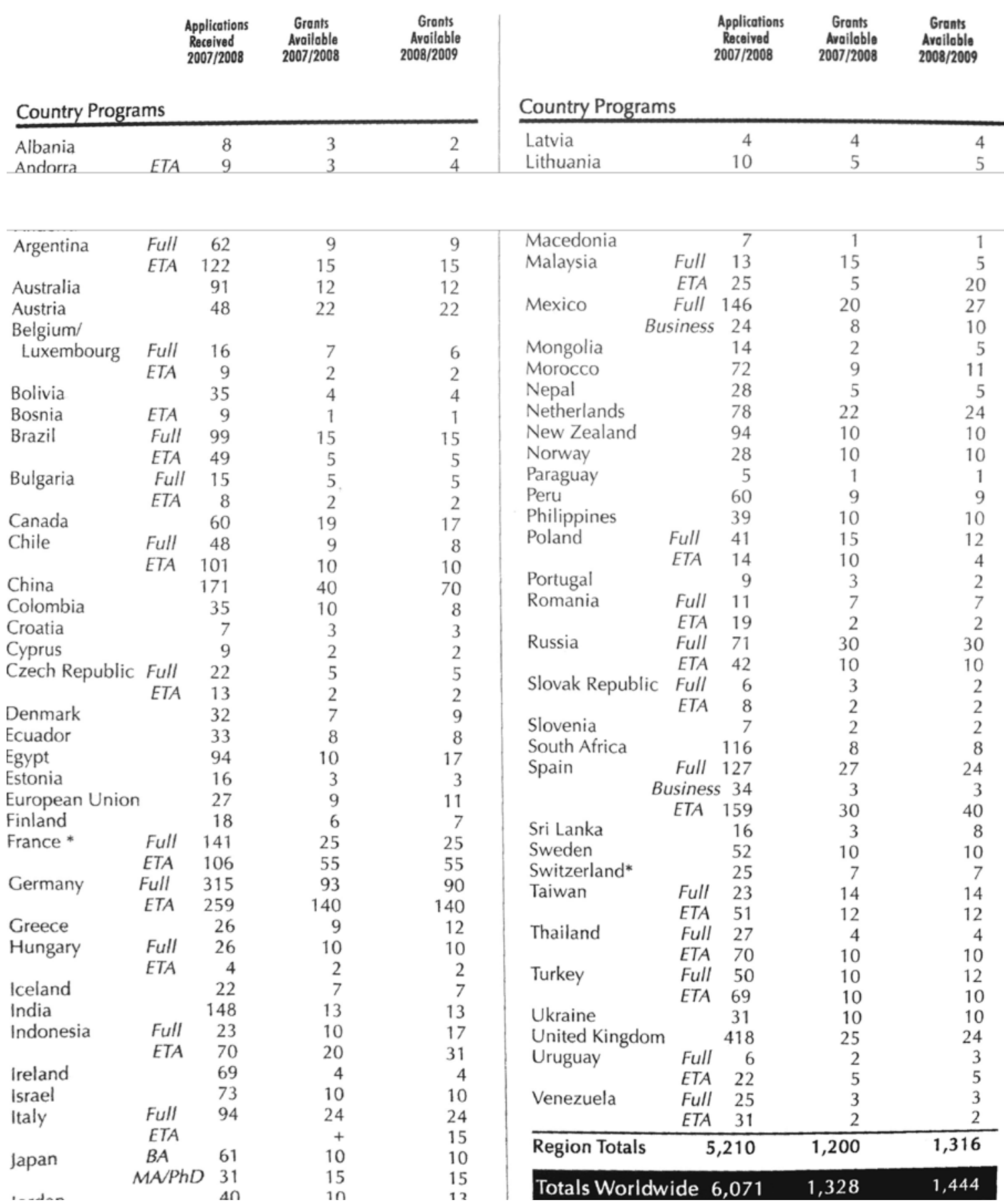

Notes: Copied from the Institute for International Education’s publication Fulbright U.S. Student Program: Grants for Graduate Study, Research, or Teaching Assistantships Abroad 2008-2009. Reprinted with permission. 
Figure 3: Annual mean competition for English Teaching Assistantships and Research Grants

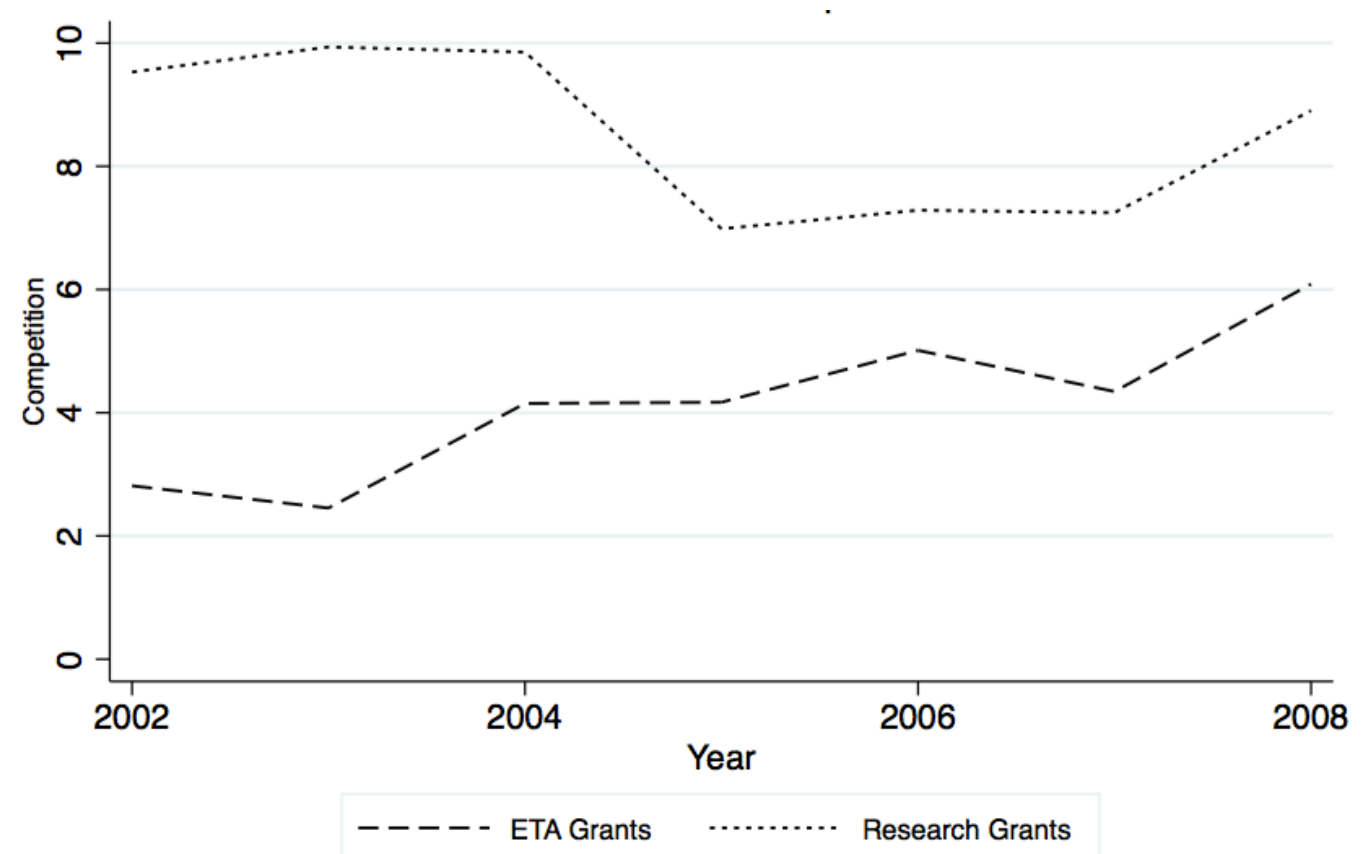

Notes: Competition is defined as the number of applications received for country c in year $t$ divided by the number of grants advertised for that country and year. Annual mean competition is weighted by the number of applications received. 
Figure 4: Annual mean competition and U.S. unemployment rate

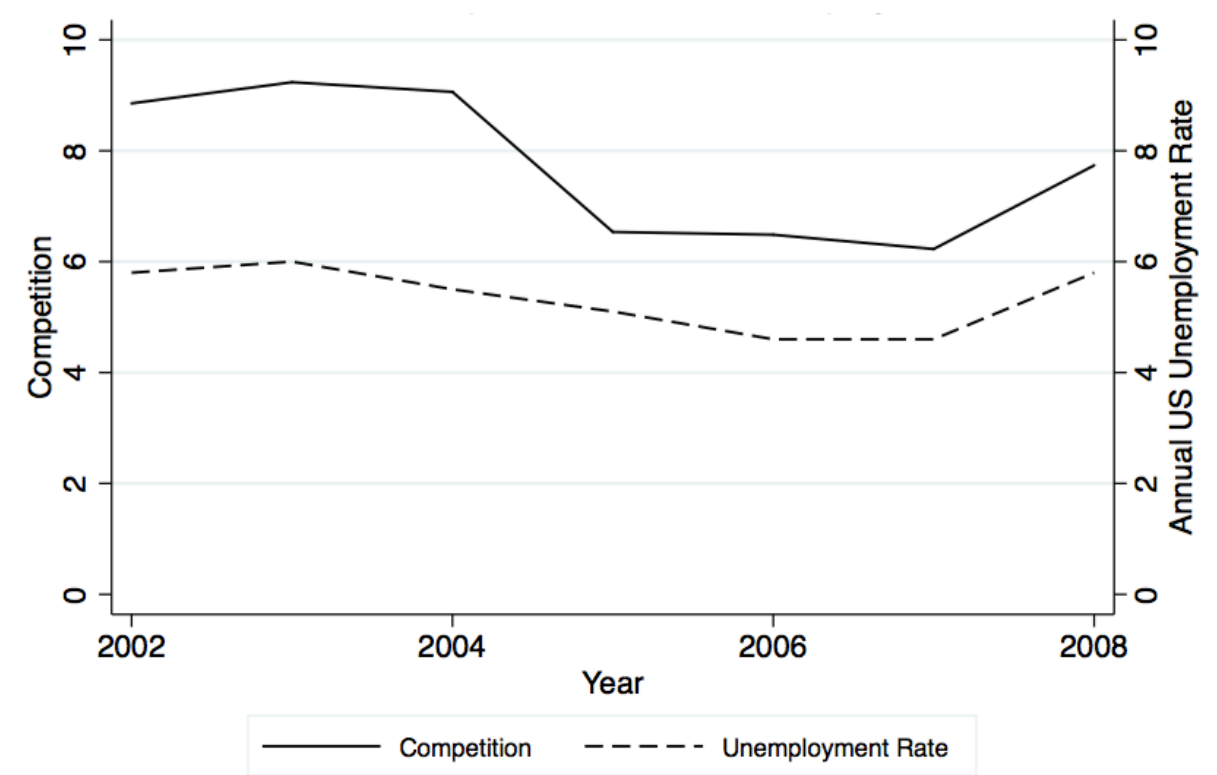

Notes: see notes to Figure 3 
Table 1: Overview of Fulbright and Covariate Data

Panel A: Summary of Fulbright data

\begin{tabular}{lcccc}
\hline & & & Teaching & Research \\
& & Aggregate & Assistant & Scholarship \\
\cline { 3 - 5 } Observations & sum & 463 & 125 & 455 \\
Countries & sum & 68 & 29 & 66 \\
Observations/Country & mean & 6.81 & 4.31 & 6.89 \\
& & & & \\
Panel B: Summary statistics & & Standard & & \\
& & & & \\
& Mean & Deviation & Minimum & Maximum \\
\cline { 2 - 5 } Competition & & & & \\
$\quad$ Aggregate & 5.49 & 4.34 & 0.00 & 37.00 \\
$\quad$ ETA Grants & 6.99 & 6.32 & 0.52 & 49.50 \\
$\quad$ Research Grants & 5.25 & 4.23 & 0.00 & 37.00 \\
Unemployment & 5.16 & 0.61 & 4.2 & 5.9 \\
GDP per Capita & $\$ 16,748.47$ & $\$ 17,213.17$ & $\$ 236.71$ & $\$ 95,189.87$ \\
Population & 70.4 million & 209 million & 77,888 & 1.32 billion \\
Article Count & 26.71 & 56.11 & 0 & 455 \\
Freedom Index Dummy & & & & \\
$\quad$ Not Free & 0.05 & 0.23 & 0 & 1 \\
$\quad$ Partially Free & 0.24 & 0.42 & 0 & 1 \\
$\quad$ Free & 0.71 & 0.45 & 0 & 1 \\
\hline
\end{tabular}

Notes: Competition is defined as the number of applications received for country c in year $t$ divided by the number of grants advertised for that country and year. In Panel B, means are weighted by the number of applications received. 
Table 2: The Effect of Reported Competition on Realized Competition

\begin{tabular}{|c|c|c|c|c|c|}
\hline & (1) & (2) & (3) & (4) & (5) \\
\hline $\begin{array}{l}\text { In(reported } \\
\text { competition) }\end{array}$ & $\begin{array}{c}0.879 * * * \\
(0.043)\end{array}$ & $\begin{array}{l}0.167 * \\
(0.084)\end{array}$ & $\begin{array}{l}0.151^{*} \\
(0.081)\end{array}$ & $\begin{array}{l}0.140^{*} \\
(0.080)\end{array}$ & $\begin{array}{l}-0.008 \\
(0.122)\end{array}$ \\
\hline $\begin{array}{l}\text { Country Fixed } \\
\text { Effects }\end{array}$ & $\mathrm{N}$ & $\mathrm{Y}$ & $\mathrm{Y}$ & $\mathrm{Y}$ & $\mathrm{Y}$ \\
\hline Control Variables & $\mathrm{N}$ & $\mathrm{N}$ & $\mathrm{Y}$ & $\mathrm{Y}$ & $\mathrm{Y}$ \\
\hline Year Fixed Effects & $\mathrm{N}$ & $\mathrm{N}$ & $\mathrm{N}$ & $\mathrm{Y}$ & $\mathrm{Y}$ \\
\hline Time Trends & $\mathrm{N}$ & $\mathrm{N}$ & $\mathrm{N}$ & $\mathrm{N}$ & $\mathrm{Y}$ \\
\hline Observations & 457 & 457 & 457 & 457 & 457 \\
\hline Adj R-squared & 0.807 & 0.865 & 0.872 & 0.876 & 0.887 \\
\hline AIC & 269.790 & 31.347 & 9.941 & 0.895 & -131.462 \\
\hline BIC & 278.040 & 35.471 & 34.690 & 50.392 & -86.091 \\
\hline \multicolumn{6}{|c|}{$\begin{array}{l}\text { Notes: Realized competition is defined as the number of applications received for country c in } \\
\text { year t divided by the number of grants advertised for that country and year. Reported } \\
\text { competition is defined as the reported number of applicants divided by the reported number of } \\
\text { grants for the previous year in the current year’s competition statistics. The dependent variable in } \\
\text { all regressions is ln(realized competition). Control variables include the natural log of gross } \\
\text { domestic product per capita, the natural log of population, dummy variables indicating freedom } \\
\text { index ("Not Free" and "Partially Free"; "Free" is the excluded variable), and article count in The } \\
\text { Economist. Standard errors are shown in parentheses and are clustered at the country level. *, **, } \\
\text { and *** indicate significance at } 10 \%, 5 \% \text { and } 1 \% \text {, respectively. }\end{array}$} \\
\hline
\end{tabular}


Table 3: The Effects of U.S. Unemployment Rate and Grant Type on Realized Competition

\begin{tabular}{|c|c|c|c|c|}
\hline & $(1)$ & $(2)$ & (3) & $(4)$ \\
\hline $\ln$ (reported competition) & $\begin{array}{l}-0.005 \\
(0.124)\end{array}$ & $\begin{array}{c}0.044 \\
(0.122)\end{array}$ & $\begin{array}{c}0.048 \\
(0.123)\end{array}$ & $\begin{array}{c}0.048 \\
(0.124)\end{array}$ \\
\hline $\begin{array}{l}\text { ln(reported competition) } \\
\text { x unemployment }\end{array}$ & $\begin{array}{c}-0.058^{* *} \\
(0.028)\end{array}$ & & $\begin{array}{l}-0.054 * \\
(0.030)\end{array}$ & $\begin{array}{l}-0.051^{*} \\
(0.030)\end{array}$ \\
\hline $\begin{array}{l}\text { ln(reported competition) } \\
\text { x ETA }\end{array}$ & & $\begin{array}{c}-0.405^{* *} \\
(0.183)\end{array}$ & $\begin{array}{c}-0.397 * * \\
(0.186)\end{array}$ & $\begin{array}{l}-0.373 \\
(0.240)\end{array}$ \\
\hline $\begin{array}{l}\text { ln(reported competition) } \\
\text { x ETA x unemployment }\end{array}$ & & & & $\begin{array}{l}-0.111 \\
(0.347)\end{array}$ \\
\hline unemployment & $\begin{array}{l}-0.305 \\
(3.515)\end{array}$ & & $\begin{array}{l}-0.045 \\
(3.811)\end{array}$ & $\begin{array}{l}-0.133 \\
(3.815)\end{array}$ \\
\hline unemployment $x$ ETA & & & & $\begin{array}{c}5.188^{* * *} \\
(1.883)\end{array}$ \\
\hline Country Fixed Effects & $\mathrm{Y}$ & $\mathrm{N}$ & $\mathrm{N}$ & $\mathrm{N}$ \\
\hline Country-Type Fixed Effects & $\mathrm{N}$ & $\mathrm{Y}$ & $\mathrm{Y}$ & $\mathrm{Y}$ \\
\hline Control Variables & $\mathrm{Y}$ & $\mathrm{Y}$ & $\mathrm{Y}$ & $\mathrm{Y}$ \\
\hline Year Fixed Effects & $\mathrm{Y}$ & $\mathrm{Y}$ & $\mathrm{Y}$ & $\mathrm{Y}$ \\
\hline Time Trends & $\mathrm{Y}$ & $\mathrm{Y}$ & $\mathrm{Y}$ & $\mathrm{Y}$ \\
\hline Observations & 457 & 571 & 571 & 571 \\
\hline Adj R-squared & 0.888 & 0.888 & 0.889 & 0.889 \\
\hline
\end{tabular}

Notes: See notes to Table 2. Unemployment data is centered about mean unemployment from 2002-2008. 